\title{
Breast augmentation with an unknown substance
}

\author{
Lamya Ebrahim, ${ }^{1}$ David Morrison, ${ }^{2}$ Alan Kop, ${ }^{2}$ Donna Taylor ${ }^{1,3}$
}

${ }^{1}$ Department of Radiology, Royal Perth Hospital, Perth, Western Australia, Australia ${ }^{2}$ Department of Medical Engineering and Physics, Royal Perth Hospital, Perth, Western Australia, Australia

${ }^{3}$ School of Surgery, University of Western Australia, Perth, Australia

\section{Correspondence to} Dr Donna Taylor, Donna.Taylor@health.wa.gov. au

Accepted 25 May 2014

\section{SUMMARY}

Before the widespread use of silicone implants various foreign substances were injected directly into the breasts. The nature of these materials sometimes remains unknown and can cause various complications requiring surgical intervention. Preoperative diagnostic imaging can help characterise the type and distribution of the injected material, thereby assisting in making decisions regarding treatment. We report a case of breast augmentation with an unknown substance, aiming to highlight some imaging characteristics of different breast augmentation substances.

\section{BACKGROUND}

In the 1950s, synthetic materials called organogens composed of petroleum jelly, paraffin or injectable silicone gel were commonly used for breast augmentation, particularly in Asian countries. In the 1970s, silicone mammary prostheses became popular. Hydrogel filled implants or injectable hydrogel, for example polyacrylamide, have been in use since the 1990s. ${ }^{1}$

Various complications are seen following breast augmentation, including failure of the implant shell (where present) and spread of the implant material. The latter may either be contained within the fibrous capsule or dispersed into the surrounding tissues. Identification of the type of implant material is important in planning treatment, in particular surgical removal of the material.

The exact number of patients who have suffered from polyacrylamide hydrogel injection complications is unknown. However, the rising number of lawsuits in courts led the Chinese State Food and Drug Administration to call for an immediate ban on the production, sale and use of polyacrylamide hydrogel in $2006 .^{2}$

While mammography can distinguish between saline and silicone material due to differences in radio-opacity, it is unable to distinguish between other substances; ultrasound is also of little value.

MRI is the technique of choice for assessment of breast implant integrity and complications, and the use of different pulse sequences may help differentiate between some of these implanted materials. Nuclear magnetic resonance (NMR) spectroscopy shows promise in the accurate identification of augmentation material, thus aiding in planning treatment.

\section{CASE PRESENTATION}

A 54-year-old woman with high familial risk of breast cancer presented with a 6-month history of bilateral upper outer quadrant breast lumps and pain, more noticeable on the right. There was no history of previous breast surgery; however, the patient said she had undergone injections of an unknown substance into both breasts 20 years ago in China for breast enlargement.

\section{INVESTIGATIONS}

On clinical examination there was mild breast asymmetry with bilateral palpable firm lumps. No lymphadenopathy was noted and there was no visible surgical scar.

Mammography demonstrated more than 75\% fibroglandular tissue, containing radio-opaque
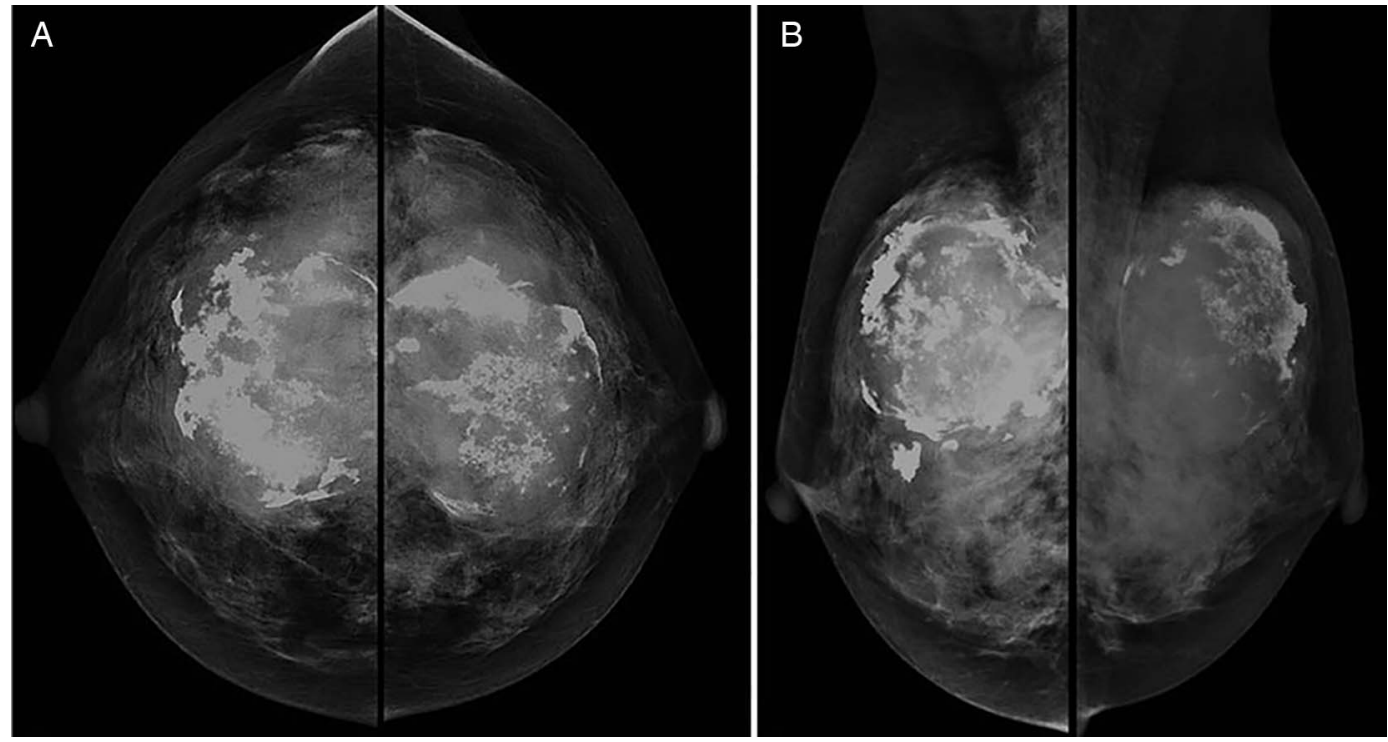

Figure 1 ( $A$ and $B$ ) Craniocaudal and mediolateral oblique mammograms. More than $75 \%$ fibroglandular density containing radio-opaque foreign material, with what appears to be areas of capsular calcification. 
A

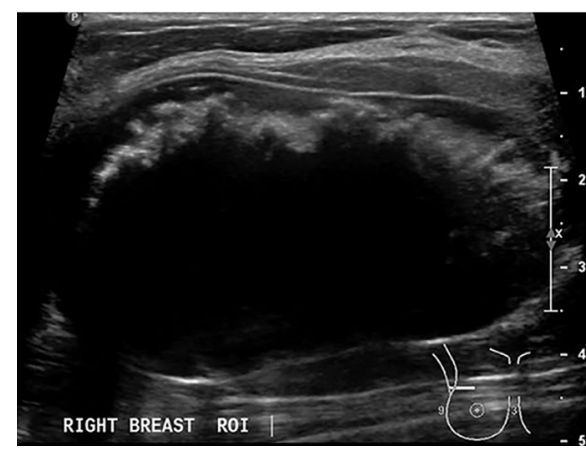

B

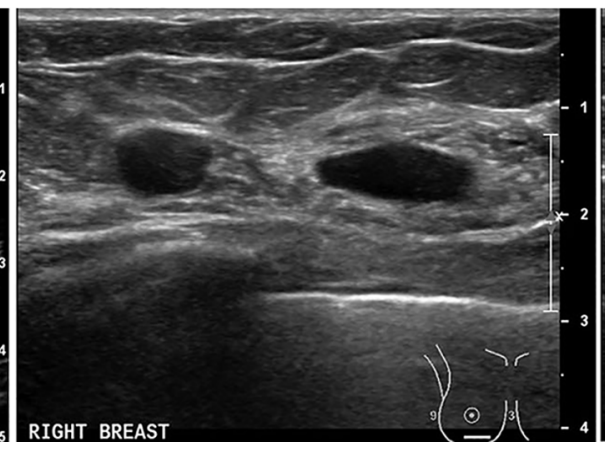

C

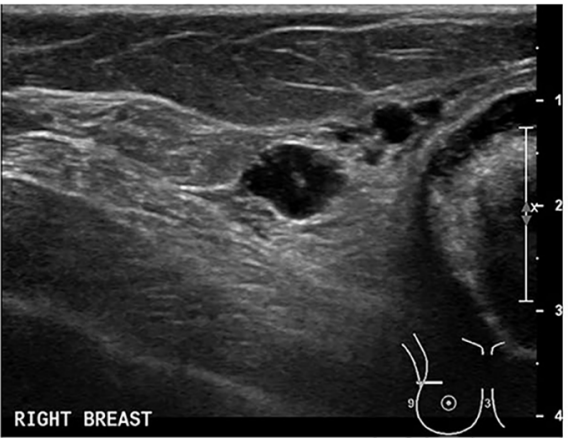

Figure 2 (A-C) Breast ultrasound images. Multiple bilateral hypoechoic masses, some containing echogenic foci with posterior acoustic shadowing silicone cysts.

foreign material, with what appeared to be areas of capsular calcification. This was thought to represent silicone implants with areas of dystrophic calcification (figure 1).

On ultrasound the palpable lumps corresponded to large hypoechoic masses, some containing echogenic foci with posterior acoustic shadowing consistent with calcification. The remainder of the breasts contained multiple small rounded hypoechoic masses, some containing turbid material, presumed to represent areas of benign cystic breast change or possibly silicone cysts (figure 2). There were no findings to suggest malignancy and the axillary lymph nodes appeared normal. Although unusual, these sonographic features were thought to represent silicone implants which had undergone extracapsular rupture and extravasation or, less likely, due to areas of free silicone injection.

MRI was performed using a $1.5 \mathrm{~T}$ Siemens Sonata, with the following sequences; T2 tirm TI 400 (silicone suppression), T2 tirm TI 150 (fat suppression), T2 tirm silicone-specific sequence with fat and water suppression, as well as precontrast and postcontrast T1 (intravenous gadolinium was given in view of the patient's strong family history).

Contrary to the mammographic appearance suggesting extensive fibroglandular tissue, MRI showed approximately 25\% fibroglandular tissue displaced anteriorly by areas of low T1 and high T2 foreign material. This material consisted of a large central component with a thin low signal rim within which were shaggy discontinuous areas of signal void, consistent with the mammographic calcification (figures 3 and 4). Multiple bilateral smaller locules with similar characteristics were noted, extending to the subpectoral and interpectoral regions on the left and presternal area on the right (figures 3 and 4). There was no intrathoracic extension and no axillary nodal involvement. No findings to suggest an inflammatory reaction were present and no features of malignancy. The signal characteristics of the material were inconsistent with those of silicone and suggestive of polyacrylamide gel.

Given the patient's symptoms and concerns regarding possible complications from the implanted material, including malignancy, ${ }^{3}$ it was decided to attempt further characterisation of the material by obtaining a sample for NMR. With the patient's consent three passes with an $18 \mathrm{G}$ needle were performed using ultrasound guidance. Owing to marked viscosity of the material only a small amount $(40 \mathrm{~g})$ of thick colourless gelatinous material was obtained (figure 5).

NMR was performed on samples of the explanted polymeric material according to previously published methods. ${ }^{1} \quad 4 \quad 5$ Solution state 13C NMR spectroscopy experiments were performed using a Bruker Avance $500 \mathrm{MHz}$ NMR spectrometer with the samples dissolved in deuterium oxide $\left(\mathrm{D}_{2} \mathrm{O}\right)$. The peaks in the NMR results which correspond to polyacrylamide were barely distinguishable above the noise, thus the analysis was inconclusive. However, there were no other peaks to indicate this was another polymer. Possible reasons for this included the length of time the material had been in situ (which may have led to degradation of the polymeric material) and, more
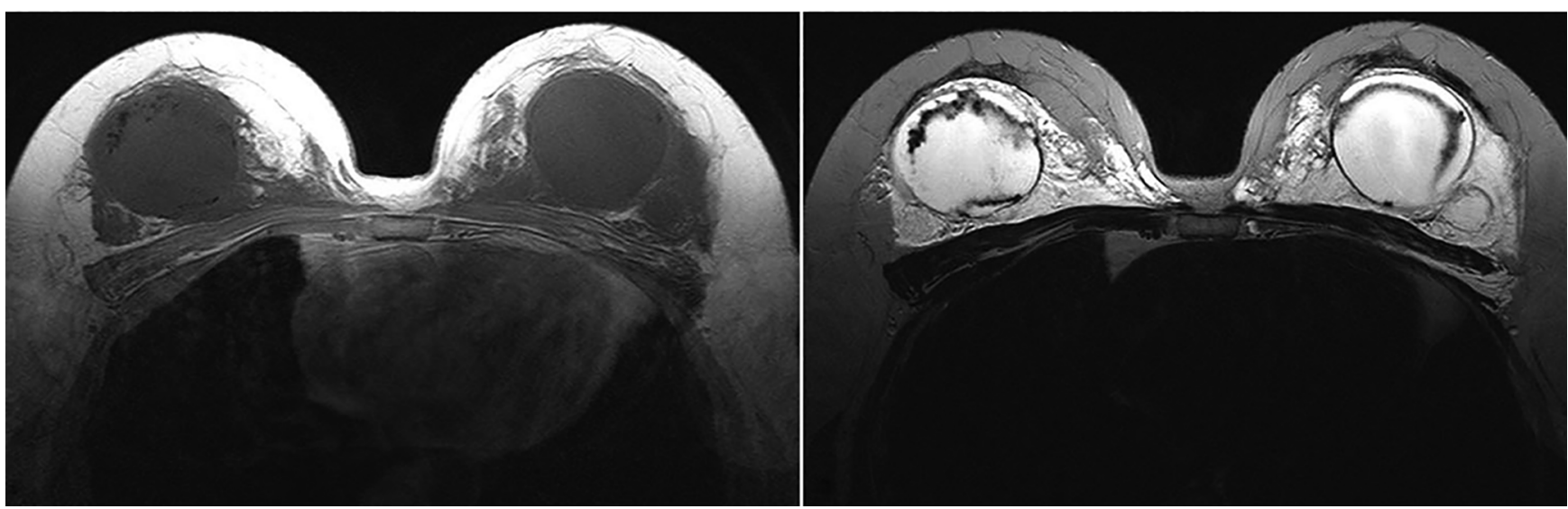

Figure 3 (A and B) Bilateral breast MRI T1 and T2 weighted sequences. Retroglandular breast augmentation material, hypointense on T1, hyperintense on $\mathrm{T} 2$ with low signal foci. 
A

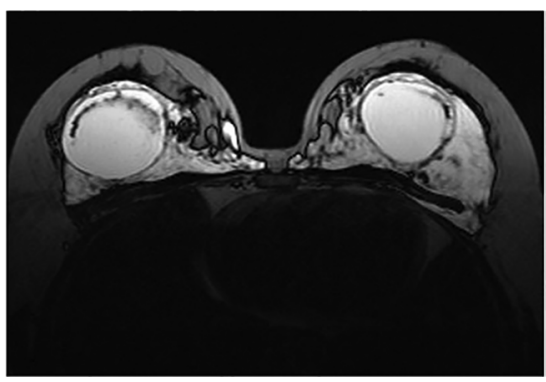

B

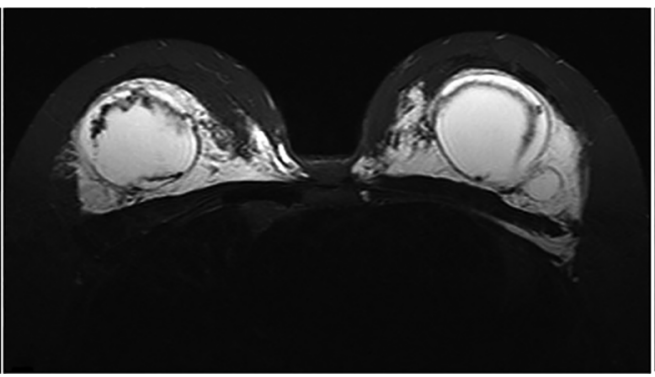

C

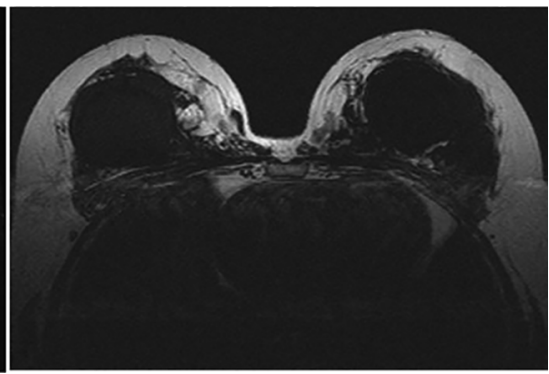

Figure 4 (A-C) Bilateral breast MRI. (A) T2 TI 400, (B) T2 TI 150, (C) T2 silicone fat suppressed, water suppressed (FSWS). There is no signal loss in the silicone-specific sequence $(A)$ and in the fat suppressed sequence (B). In the fat and water suppressed sequence (C) the injected material has dropped its signal, indicating it hydrophilic in nature. The images demonstrate a large central component, containing thin low signal rim with discontinuous areas of signal void, consistent with the mammographic calcification. There is an extension to the subpectoral and interpectoral regions on the left, and presternal area on the right, with no intrathoracic extension.

likely, the small quantity of material available for analysis, which has previously been reported as a limiting factor in the NMR analysis of explanted polyacrylamide hydrogel materials. ${ }^{5}$

\section{OUTCOME AND FOLLOW-UP}

Given the extensive spread of the implanted material it was decided surgical removal was not feasible and the patient agreed to conservative management.

The high density of the material and extensive calcification on mammography means that this modality will not be useful as a screening tool for this particular patient.

In view of the strong family history of breast cancer, ongoing surveillance with contrast enhanced breast MRI has been recommended.

\section{DISCUSSION}

The ease of injection and the presumed safety of the injected materials have attracted many women to have breast augmentation by direct injection. Because the injection is performed blindly using a percutaneous large bore needle without imaging guidance, the substance can be injected in any layer of the breast and in different layers of both breasts, with variable resultant complications.

Intraglandular injection will displace the breast lobules and, if injected in large amounts, may result in glandular atrophy and skin necrosis. Intrapectoral injection will split and dissect the muscle fibres, giving a pseudo linguine sign on MRI. ${ }^{6}$

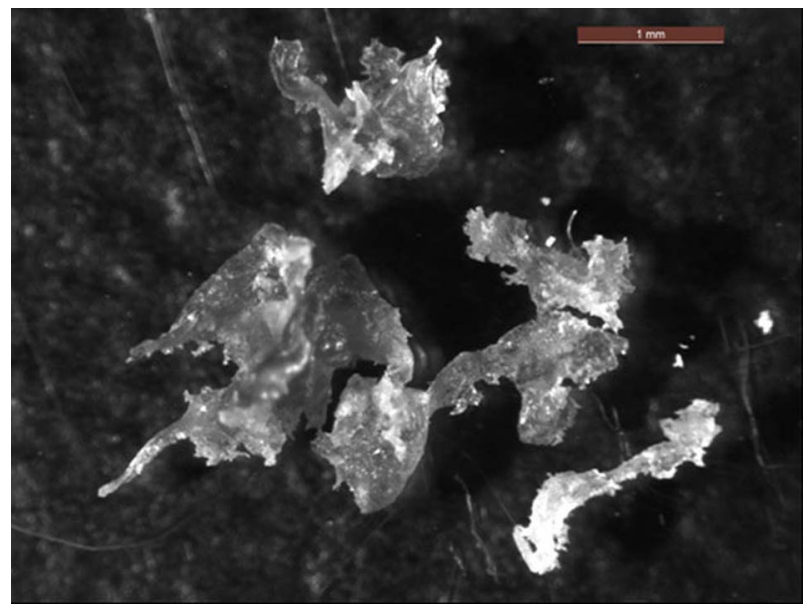

Figure 5 Stereomicroscope image (Leica MZ10) of aspirated polymer substance, scale bar represents $1 \mathrm{~mm}$.
Christensen et $a l^{7}$ described how injected polyacrylamide gel fails to develop a fibrous capsule and is only encapsulated by thin fibrous tissue. This explains why it can easily migrate through different tissue planes and form multiple small pockets, posing a significant challenge to surgeons if complete removal of the material is required. Failure to use aseptic technique during injection will predispose to infection and abscess formation with consequent morbidity.

MRI is the imaging study of choice to evaluate the nature and extent of various complications, specifically using axial and sagittal T2 W sequences.

Fast spin echo T2W sequences without fat suppression are the most useful sequences to demonstrate the location and extent of the displaced gel. ${ }^{6}$

In general, substances that are hypointense on T1W sequences and hyperintense on $\mathrm{T} 2 \mathrm{~W}$ sequences contain hydrophilic materials.

The MRI characteristics of the implanted material compared with the common breast augmentation substances are shown in table $1 .^{8}$

Intravenous contrast administration helps identify adjacent inflammation $^{6}$ and contrast enhanced MRI may be the only feasible modality for breast cancer screening in these women, as the injected material obscures the breast parenchyma, limiting mammographic assessment.

NMR spectroscopy is a promising technique able to produce a specific spectral pattern for each breast augmentation material, enabling the identification of its constituents. ${ }^{1}$ To the best of our knowledge, however, it has only been used on explanted materials. We postulate that positive identification of the injected material for our patient may have been possible if a

Table 1 MRI characteristics of the implanted material compared with common breast augmentation substances

\begin{tabular}{ll}
\hline Type of augmentation & MRI Characteristics \\
\hline Silicone & T2-high signal, T1-low signal, silicone \\
& sensitive-high signal \\
T2-high signal, T1-low signal, silicone & sensitive-low signal \\
Saline & T2-high signal, T1-high signal, silicone \\
& sensitive-low signal, fat suppression-low \\
Autologous fat & signal, with or without peripheral enhancement \\
& T2-high signal with foci of low signal, T1- \\
Polyacrylamide gel (similar & low signal, silicone sensitive-low signal, with \\
findings in our case) & or without peripheral enhancement
\end{tabular}


larger quantity could have been obtained, possibly by using a 14 or even a $9 \mathrm{G}$ core biopsy needle. Further research is needed to determine the minimum amount of material needed to enable definitive spectroscopic analysis.

\section{Learning points}

- MRI is the most useful imaging technique to help show the distribution of injected augmentation materials and to differentiate between 'free' injections and complicated prostheses, thereby assisting treatment planning.

- The use of different MRI sequence combinations may help differentiate between silicone, paraffin, autologous fat and polyacrylamide gels by their differing signal intensities.

- Percutaneous sampling techniques could potentially provide enough material to allow for accurate identification of such injected substances using nuclear magnetic resonance spectroscopy.

Acknowledgements The authors express their appreciation to Dr Keiko Hirakawa of the Department of Legal Medicine, Nippon Medical School, Tokyo, Japan and to
Associate Professor Lindsay Byrne of the Centre for Microscopy, Characterisation and Analysis at the University of Western Australia, Perth, Australia for their assistance with the NMR analysis. Barbara Taylor for assisting with the preparation of the manuscript.

Competing interests None.

Patient consent Obtained.

Provenance and peer review Not commissioned; externally peer reviewed.

\section{REFERENCES}

1 Kawahara S, Hyakusoku H, Ogawa R, et al. Clinical imaging diagnosis of implant materials for breast augmentation. Ann Plast Surg 2006;57:6-12.

2 Cheng M, Ho C, Cheung W. Polyacrylamide hydrogel injection for breast enhancement: should it be banned? Plast Reconstr Surg 2008;122:94e-5e.

3 Acrylamide toxicity: Research to address key data gaps. US Department of Health and Human Services Food Advisory Committee Meeting: Acrylamide. February 24-25, 2003.

4 Okuda T, Hirakawa K, Orbay $\mathrm{H}$, et al. The use of NMR spectroscopy for identifying unknown foreign materials after aesthetic procedures. J Plast Reconstr Aesthet Surg 2012;65:692-4.

5 Ono S, Ogawa R, Hyakusoku H. Complications after polyacrylamide hydrogel injection for soft-tissue augmentation. Plast Reconstr Surg 2010;126:1349-57.

6 Lui $C$, Ho C, lu $P$, et al. Evaluation of MRI findings after polyacrylamide gel injection for breast augmentation. AJR Am J Roentgenol 2008;191:677-88.

7 Christensen L, Breiting V, Aasted A, et al. Long-term effects of polyacrylamide hydrogel on human breast tissue. Plast Reconstr Surg 2003;111:1883-90.

8 Berg W. Diagnostic imaging. Breast. Post-operative imaging findings. Utah: Amirsys, 2006.

Copyright 2014 BMJ Publishing Group. All rights reserved. For permission to reuse any of this content visit http://group.bmj.com/group/rights-licensing/permissions.

BMJ Case Report Fellows may re-use this article for personal use and teaching without any further permission.

Become a Fellow of BMJ Case Reports today and you can:

- Submit as many cases as you like

- Enjoy fast sympathetic peer review and rapid publication of accepted articles

- Access all the published articles

- Re-use any of the published material for personal use and teaching without further permission

For information on Institutional Fellowships contact consortiasales@bmjgroup.com

Visit casereports.bmj.com for more articles like this and to become a Fellow 